\title{
Intra-MNC's Knowledge Transfer: A Three Gaps Model
}

\author{
Wang-Fang $^{1}$ and Ho-Yeol Bang ${ }^{2 *}$ \\ ${ }^{1}$ Ph. D. Candidate, School of Business, Pusan National University, \\ Geumjung-gu, Busan,609-735, Koreawf47@163.com \\ ${ }^{2}$ Professor, School of Business, Pusan National University, \\ Geumjung-gu, Busan, 609-735, Korea \\ hybang@pusan.ac.kr
}

\begin{abstract}
We explored comprehensively the key factors in the process of knowledge transfer between a MNC's $H Q$ and foreign subsidiaries, and suggested a new model called as a three gaps model of intra-MNC's knowledge transfer. Even the importance of knowledge transfer is widely acknowledged, there are limited empirical works about emerging MNCs. Our finding can help managers of emerging MNCs effectively control foreign subsidiaries and successfully achieve knowledge transfer.
\end{abstract}

Keywords: knowledge transfer, gap model, foreign subsidiary, absorptive capacity

\section{Introduction}

The conceptualization of a multinational corporation (MNC) as a knowledge creator and transferor has inspired a recent stream of research on the creation, assimilation and diffusion of a MNC's internal knowledge. A common theme in this line of research is that a MNC might develop knowledge in one location and then exploit it in other locations, implying internal transfer of knowledge by a MNC. Transfer of knowledge does not denote a full replication of the knowledge in receiving units (such as overseas subsidiaries). The key element in knowledge transfer is not the underlying (original) knowledge, but rather the extent of how much receiving units acquire useful knowledge and utilize it in their own operations. As overseas subsidiaries are established in novel and foreign environments, there are differences in cultural, linguistic, and institutional environments. These differences affect the international knowledge transfer within a MNC network.

The prior research on knowledge transfer among MNC units has attempted to identify critical factors that inhibit or facilitate knowledge transfer, such as receiving units' absorptive capacity or motivational factors to acquire knowledge. According to the literature review [5] and [17], these two factors stand out and have a particular importance in determining the success of knowledge transfer. Subsidiaries whose employees are highly motivated and with high absorptive capacity will be more competent as exchange partners, and they will also be better equipped to acquire and use the knowledge that they receive. Absorptive capacity, however, has been treated mainly as a cognitive barrier apart from motivational factors [6], [15-16]. Motivational factors also have most often been considered separately from absorptive capacity. For example, Szulanski (1996) focused only on the lack of motivation of source and recipient units, and Gupta and Govindarajan (2000) also treated the motivational disposition of source and target units but absorptive capacity.

Considering the limitation of the prior research, it is necessary to develop a comprehensive rather than parsimonious model to reflect a multidimensional aspect of international knowledge transfer. The aim of this paper is to develop an intra-MNC's knowledge transfer model called as 'a three gaps model', which is supposed to explain the

*Corresponding Author 
multidimensional aspect of international knowledge transfer. Three gaps include a knowledge gap, a culture gap and a communication gap between a sender and a receiver of knowledge. Although the importance of knowledge transfer is widely acknowledged, there are limited empirical works focusing MNCs in emerging countries. This study implemented questionnaire survey of MNCs located in the city of Wuhan in China.

\section{Literature Review}

To exploit the globalization trend of business environments and to overcome trade barriers (visible and invisible barriers), MNCs continually set up overseas subsidiaries. Under a unified leadership of headquarters (HQs) and global strategies, MNCs are better equipped for managing subsidiaries efficiently, enhancing the competitiveness of their products and services, and creating overall competitive advantage. A firm-specific knowledge is suggested as a fundamental source of MNCs' competitive advantage. The key for MNCs to remain invincible against the increasingly fierce global competition is the successful transfer of knowledge between HQs and overseas subsidiaries. Since 1990s MNCs' internal knowledge transfer has become a hot issue among some research field such as international business, international strategy of MNCs and knowledge management [6-7].

In general, the research on knowledge transfer has two perspectives: one focuses on the characteristics of the knowledge that is transferred [8-9] and [12], and another focuses on the processes and interactions involved in knowledge transfer [14]. This paper's orientation belongs to the latter. Knowledge transfer can occur among various entities spanning multiple levels including individuals, groups, and organizations. The recent drastic changes in the world's competitive environment provide a unique opportunity to examine how organizational globalization affects knowledge transfer.

Firms can access and absorb knowledge embedded in other organizations or in foreign countries through foreign direct investment [13]. Firms do their best to obtain knowledge from external sources when there is a significant knowledge gap between source and recipient units. The sourcing, sharing and exploiting external knowledge have significant implications to creating corporate competitiveness. The primary reason why MNCs exist is because of their ability to transfer and exploit knowledge more effectively and efficiently in an intra-corporate context than through external market mechanisms [6], [8-9].

MNCs knowledge flows may occur in multiple directions; vertically between a HQ and a subsidiary, and horizontally between different subsidiaries. At the initial stage of knowledge transfer within MNCs, the movement of knowledge is from HQs to overseas subsidiaries, and the role of each subsidiary is only a receiver and implementer. As time goes, overseas subsidiaries evolve in terms of their capabilities and strategic roles, and this evolution enables the subsidiaries to act as knowledge senders to HQs or other overseas subsidiaries [18].

A problem faced by MNCs in knowledge transfer is a knowledge gap between HQs and overseas subsidiaries. As a wide knowledge gap between senders and receivers may negatively affect the success of knowledge transfer, MNCs must decide if the receivers have enough absorptive capacity which can be defined as a receiving, absorbing, and exploiting ability of external knowledge. If a knowledge gap between HQs and subsidiaries is wide, a knowledge intermediary might be required.

The knowledge transfer analysis framework (KTA framework) is proposed by Vito Albino in 1999 [1]. The KTA framework is composed of four components: the main of transfer (actors), transfer media (media), the content of transfer (content), and transfer situation (context). The KTA framework is important because it suggested the systemic structure of knowledge transfer which provides strong support for the theoretical analysis. Three components of the KTA framework, that is, the main of transfer, transfer media and the content of transfer are a necessary condition for the occurrence of knowledge transfer. The remaining one, transfer situation, includes various internal and 
external factors influencing knowledge transfer. The internal factors include culture and value dimensions, strategy of knowledge management, evaluation and incentive system, knowledge transfer management team and so on. The external factors mean such as social or economic context and the industry or high-tech industry characteristics. These internal and external situation factors play a leading role in promoting and improving knowledge transfer activities.

Even though knowledge transfer contributes to laggard subsidiaries, a knowledge gap between participants influences the effectiveness of knowledge transfer. If the receivers' knowledge level is too low, they may have difficulty to absorb the knowledge to be transferred directly [4]. Therefore, successful knowledge transfer needs a good collaboration between partners of an equal strength. If one partner is too weak (or less developed), it is not a sustainable situation because one way flow will seriously affect collaboration needed in the international knowledge transfer.

\section{A Conceptual Framework and Hypotheses}

This paper mainly concerns intra-MNC's knowledge transfer, or knowledge transfer between a HQ and overseas subsidiaries. We conceptualized intra-MNC's knowledge transfer as a knowledge gap reduction process. The success of knowledge transfer is possible by reducing a knowledge gap between a HQ and overseas subsidiaries. To explain the knowledge gap reduction process, we suggest a model called 'a three gaps model' (see Figure 1). It focuses on gaps between senders (HQs) and receivers (overseas subsidiaries) in a knowledge transfer process. In the process of knowledge transfer, there are three potential gaps. One is called 'knowledge gap' between HQs and subsidiaries, the second, 'communication gap,' also can be referred to as 'geographical gap,' and the last one is 'culture gap,' which can be called 'psychological gap.'

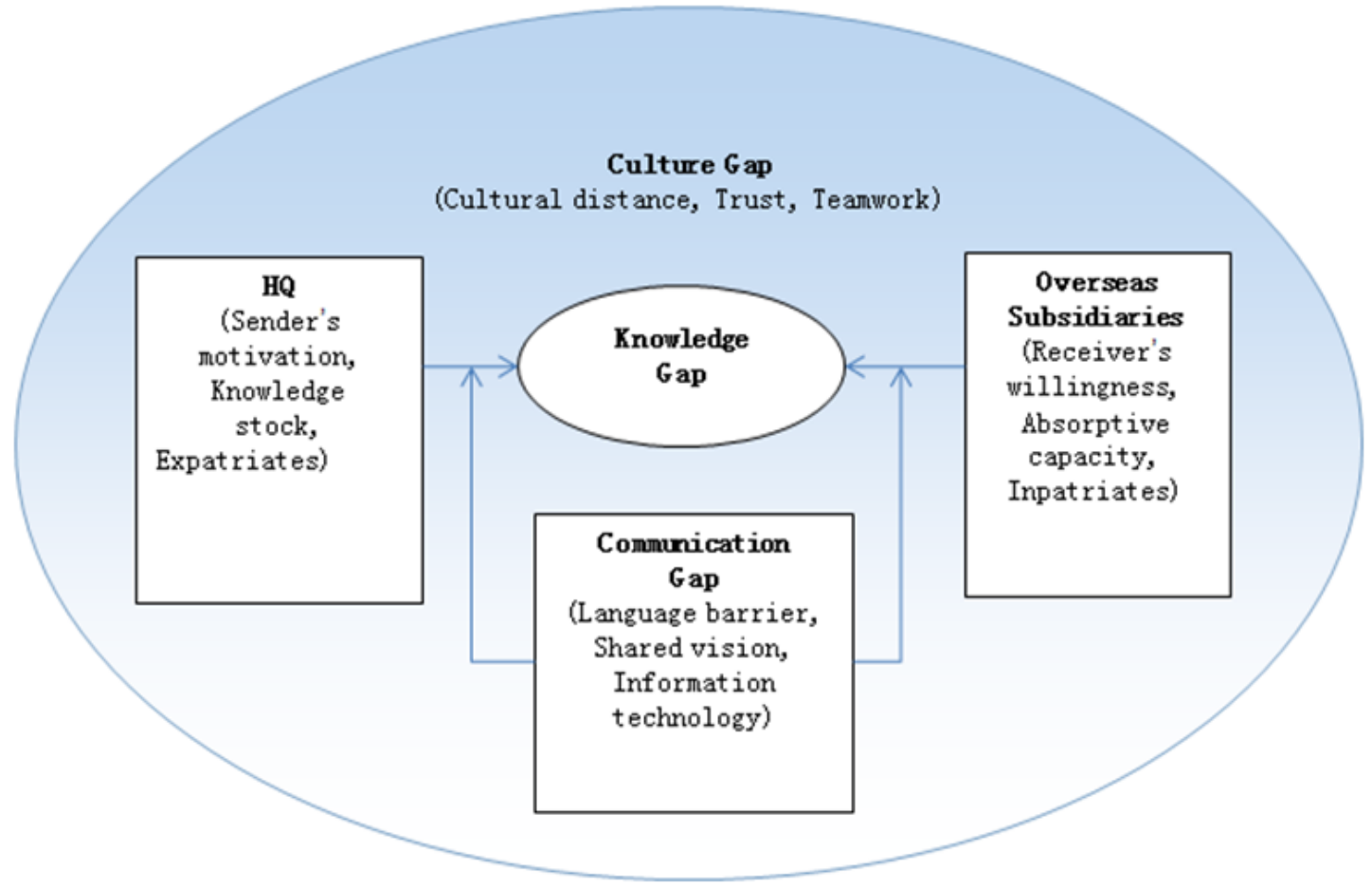

Figure 1. A Conceptual Framework of a Three Gaps Model

The goal of intra-MNC's knowledge transfer is to reduce the first gap, a knowledge gap. The outcome of knowledge transfer, how much MNCs can reduce a knowledge gap between HQs and subsidiaries, is dependent on the other two gaps, that is, a 
culture gap and a communication gap. By reducing the second and third gap, MNCs can reduce the first gap. Thus for the successful knowledge transfer, MNCs should find out mechanisms for the reduction of a culture and a communication gap.

The second gap, a culture gap, is created by the cultural difference between participants in a knowledge transfer process. It can be reduced by narrowing a cultural distance, enhancing trust and building teamwork. First, culture is a critical dimension of international knowledge transfer. It is important that all participants should understand a cultural distance from each other. Cultural literacy enables them to narrow and get over a cultural distance. Second, the success of cross-cultural knowledge transfer is also dependent on trust among participants from different cultures. Trust is extremely important for knowledge exchange because it is the basis of any fruitful collaboration. Knowledge transfer will not be possible without trust. Trust helps to establish a long-term partnership among participants and to overcome problems and unforeseen obstacles [2]. Lastly, teamwork between HQs and overseas subsidiaries is at the core of international knowledge transfer. MNCs should promote a regional and multilateral networking between HQs and overseas subsidiaries. As a reinforced form of partnership, teamwork ensures effective knowledge transfer and future exploitation of this knowledge in the targeted functions.

The third gap between participants in terms of communication level will influence the success of knowledge transfer. A communication gap is created by language barriers, conflicting visions, and inappropriate communication channels and technologies. It can be reduced by removing language barriers, sharing a common vision, establishing effective channels and utilizing ICT (information- communication-technology). First, language is a key factor as a transfer media in international knowledge transfer. Although English is the major international language, participants from Asia countries do not seem to have a good command of it. This could cause communication problems and undermine receivers' ability to understand and learn knowledge.

Second, shared vision is a crucial factor in a process of knowledge transfer. It has been suggested in the previous literature that shared vision encompasses many aspects of a cooperative relationship. The concept of shared vision is often used to refer to shared values and goals, and mutual understandings in a cooperative relationship. Shared values and understandings between participants facilitate a meaningful communication that is essential in a international knowledge transfer. A MNC's organization culture helps to build shared vision between a HQ and subsidiaries. Third, participants involved in knowledge transfer should make sure that partners agree to employ an effective information-communication-technology (ICT). A variety of ICT can be used by MNCs including international training and seminar; video-meeting; ICT system; B2B matchmaking, simple e-mail and so on. These ICTs facilitate more frequent interactions between participants without a travel in person and help international transfer of tacit knowledge.

\subsection{HQs and Knowledge Gap}

Headquarters play a critical role in coordinating, promoting, and sustaining inter-unit knowledge transfer. This study investigates how MNCs can reduce knowledge gap by influencing a knowledge transfer process. We chose sender's motivation, knowledge stock and expatriates as sender-related characteristics in intra-MNC's knowledge transfer. The following three hypotheses are developed.

Sender's Motivation. To ensure effective transfer, HQs can support transfer efforts directly by providing expertise and commitment. Such involvement makes a particular project visible, and participation in it becomes more legitimized. Specific incentives and evaluations can elicit desired behavior at the unit level [6], and active involvement by HQs may enhance and support the effectiveness of knowledge transfer, influencing overall satisfaction with the knowledge and the creation of business value. Hence, we put forward the following hypothesis: 
Hypothesis 1: Sender's motivation to share knowledge will positively reduce the knowledge gap between a HQ and overseas subsidiaries.

Knowledge Stock. Some scholars emphasize the dynamic balance between applying current knowledge (i.e., knowledge exploitation) and acquiring new knowledge (i.e., knowledge exploration). How do knowledge stocks affect knowledge transfer? Both the resource-based and knowledge-based views of the firm suggest that firms that acquire higher levels of knowledge stocks are better positioned in terms of their ability to innovate successfully [4-9]. That is, firms with a higher initial stock of knowledge, such as R\&D know-how, benefit from first-mover advantages compared with firms with low initial knowledge stocks. Hence, we put forward the following hypothesis:

Hypothesis 2: High level of knowledge stock will positively reduce the knowledge gap between a HQ and overseas subsidiaries.

Expatriates. In MNCs, expatriates are selected on the basis of their technical skills by HQs and thus may not have the 'soft skills' required for the effective knowledge transfer. Going forward, it is important to identify the specific expatriate competencies critical for successful knowledge transfer. Harvey et al., (1999) showed that the number of expatriates from the MNC has a positive effect on the scope of the knowledge transferred [7]. Through expatriation experience, expatriates can learn how to enhance their interaction into foreign subsidiaries' business activities and emotional stability. Hence, we put forward the following hypothesis:

Hypothesis 3: Expatriates (rather than inpatreates) will positively reduce the knowledge gap between a HQ and overseas subsidiaries.

\subsection{Overseas Subsidiaries and Knowledge Gap}

Prior studies have shown that recipient's absorptive capacity, willingness, and motivation had a significant on the success of knowledge transfer [15-16]. Subsidiaries with motivated employees will be more interesting as exchange partners for the other MNCs unit and they will also be better equipped for acquiring and using the knowledge that they receive. This part investigates how overseas subsidiaries can reduce knowledge gap by influencing a knowledge transfer process. We suggest receiver's willingness, absorptive capacity and inpatriates as receiver-related characteristics to develop a hypothesis.

Receiver's Willingness. Knowledge absorptive motivation (or willingness) refers to the recipient's desire to acquire and implement the knowledge being transferred. Absorptive motivation (or willingness) is also one of the key methods in the acquisition and utilization of external knowledge. Gupta and Govindarajan (2000) observed that the knowledge inflows into a subsidiary are positively associated with the motivation (or willingness) to acquire knowledge as well as the richness of transmission channels and the capacity to absorb incoming knowledge [6]. They also report that knowledge flows out of the subsidiaries depend heavily upon the motivation (willingness) of the subsidiary to share knowledge with other organizations. Hence, we put forward the following hypothesis:

Hypothesis 4: Receiver's willingness to acquire knowledge will positively reduce the knowledge gap between a HQ and overseas subsidiaries.

Absorptive Capacity. It has been proposed that absorptive capacity of the receiving unit is the most significant determinant of internal knowledge transfer in MNCs [6]. In some studies absorptive capacity has been treated as a cognitive barrier to knowledge transfer. Szulanski (2000) argued that the 'lack of recipient's absorptive capacity' was 
an important determinant of 'stickiness' [16]. Hence, we put forward the following hypothesis:

Hypothesis 5: Absorptive capacity will positively reduce the knowledge gap between a HQ and overseas subsidiaries.

Inpatriates. As growing market opportunities in less developed economies have contributed to a shift concerning the major assignment destinations. The benefits of inpatriation strategies are clear. They inject cultural diversity into the HQ operations, they provide communication links to the operations and institutions of countries from which they came and they offer a cost-effective alternative to situations where expatriates are less likely to succeed [7]. Therefore the inpatriation of foreign nationals to the MNC's HQ is considered to be an effective way to master challenges arising from the increased global scope of MNC activities. It is argued that inpatriates fulfill an important boundary spanning role since they develop knowledge of both the HQs and the local subsidiary context. Hence, we put forward the following hypothesis:

Hypothesis 6: Inpatriates will positively reduce the knowledge gap between a HQ and overseas subsidiaries.

\subsection{Communication Gap and Knowledge Gap}

The role of communication in knowledge transfer is to bridge the communication gap between the knowledge senders and the receivers to fill the receiver's technical gap. As Szulanski (2000) pointed out, such a communication gap, especially within MNCs may be caused by incompatibilities of language, coding schemes, and cultural conventions. Prior researches have indicated that frequent communication between the knowledge senders and receivers results in greater knowledge transfer. Therefore, as media factor of knowledge transfer in MNCs, we chose language barrier, shared vision and information technology as communication gap dimensions to develop a hypothesis.

Language Barrier. The frequently cited article on international knowledge transfer is Kogut and Zander (1993). They argue that a shared language enhances communication and exchanges in general. Faced with the language issue in internal inter-unit information and knowledge transfer, over time, MNCs tend to move towards the use of a common corporate language, and sometimes more than one [3]. Wherever language is a barrier to the development of close personal relationships, the level of suspicion, mistrust and conflict between HQs and its overseas subsidiaries will be heightened. Such mistrust will cause the HQs to be more formal and less subjective in its evaluation of subsidiary performance, and may also hinder collaborative processes such as knowledge and technology transfer. Hence, we put forward the following hypothesis:

Hypothesis 7: language barrier will negatively reduce the knowledge gap between a HQ and overseas subsidiaries.

Shared Vision. We know that shared values and common goals between parties in an exchange relationship facilitate effective communication that is essential in both the exchange and combination required for knowledge transfer [10]. In MNCs, HQsubsidiary relationship is inherently long-term and cooperative by nature. Higher level of shared vision may act as a counter force making subsidiaries be more willing to accept the inflow of knowledge, especially those types of knowledge perceived as contextually irrelevant and low in commercial value for the subsidiary. Therefore, it's shown that shared vision is more important in the knowledge transfer in MNCs between HQs and overseas subsidiaries. Hence, we put forward the following hypothesis:

Hypothesis 8: Shared vision will positively reduce the knowledge gap between a HQ and overseas subsidiaries. 
Information Technology. The diffusion of information flow involves face-to-face contacts and mediated by communication mechanisms (ex. telephone and email exchanges). Gupta and Govindarajan (2000) had shown that communication patterns, density and effectiveness effect innovation diffusion and organizational integration in MNCs. Similarly, extensive inter-unit communication is seen as crucial for knowledge exchange and innovation diffusion in the MNCs' internal network. In the recently, represented by an ICT, information technology and knowledge transfer need to fit the overall strategy of both parties in MNCs. Hence, we put forward the following hypothesis:

Hypothesis 9: Information technology will positively reduce the knowledge gap between a HQ and overseas subsidiaries.

\subsection{Culture Gap and Knowledge Gap}

Some context factors such as culture gap between home and host countries have been shown to influence the success of knowledge transfer in MNCs. Typically, corporate expand their business to other countries by the ownership of either wholly-owned subsidiaries (WOS) or international joint ventures (IJV) with local partners. Our paper investigates how culture gap can reduce knowledge gap by influencing knowledge transfer process. As context factor of knowledge transfer in MNCs, we chose cultural distance, trust, teamwork as culture gap related dimensions to develop a hypothesis.

Cultural Distance. The scope of culture can be as small as a company, or as wide as a country. Despite culture being a complicated, intangible, and vague construct that is very difficult to gauge accurately, a cultural distance has been used extensively in cross-cultural studies and, accordingly, various distance frameworks have been developed to measure cultural differences across countries. Cultural distance refers to the degree to which one nation's culture is similar to or different from that of another nation. Some studies in MNCs have shown that the greater the cultural distance between the host country and home country is, the more difficult the knowledge transfer. Some results revealed that the success of knowledge source and recipient. Hence, we put forward the following hypothesis:

Hypothesis 10: cultural distance will negatively reduce the knowledge gap between a HQ and overseas subsidiaries.

Trust. Knowledge transfer has been determined as one of the key ways that lead to the creation of sustainable competitive advantage for firms and to the success of learning alliances. Furthermore, trust enhances the effectiveness of this process [2]. Trust is not only major factors for knowledge transfer within a $\mathrm{MNC}$, but also it is the basis of any collaboration and is critical for relationship building, and that it affects knowledge transfer indirectly through its effect on other factors. In other words, knowledge transfer won't be possible without trust. Hence, we put forward the following hypothesis:

Hypothesis 11: Trust will positively reduce the knowledge gap between a HQ and overseas subsidiaries.

Teamwork. Teamwork is the assignment of work to groups of employees with various skills who interact to assemble a product or provide a service. It showed that teamwork is very important for MNCs, which have employees from different countries around world. Specially, in overseas subsidiaries, most of employees who is filled with different cultural background from home countries need to teamwork with a HQ' employees. Gupta and Govindarajan (2000) found that subsidiaries with less decision-making autonomy by a $\mathrm{HQ}$, receive greater knowledge transfer from MNCs. Research on knowledge transfer emphasizes the importance of teams within MNCs. Teams operating within the subsidiary context may become isolated from the rest of the 
MNCs, with negative consequences for access to and transfer of relevant, useful knowledge, thus reducing the subsidiary's absorptive capacity. Knowledge can easily become locked within a subsidiary-based team thereby restricting sending capacity. Hence, we put forward the following hypothesis:

Hypothesis 12: Teamwork will positively reduce the knowledge gap between a HQ and overseas subsidiaries.

\section{Method and Empirical Analysis}

\subsection{Operational Definition}

The majority of measurement items are derived from the prior research, and some items were deleted or modified for this study due to semantic problems during translation. A 5-point Likert-type scale was used for the measurement with anchors ranging from "completely disagree" (1) to "completely agree" (5). In order to obtain the reliability of the scales, Cronbach's Alpha coefficient was calculated. Items operationalized to measure the constructs are shown in the appendix.

\subsection{Questionnaire Structure and Data Collection}

According to the previous literature, the questionnaire was consisted of five constructs: HQ (11 items), overseas subsidiaries (12 items), communication gap (11 items), culture gap ( 12 items) and knowledge gap ( 3 items). The total 49 questions were intended to measure the perception of a CEO or a senior manager who was working in MNCs. The respondents were requested to check one of 5-point Likert scales, that is, from 'completely agree' to 'completely disagree' (1=completely disagree, $5=$ completely agree).

As the topic of this study is the knowledge transfer from HQs to subsidiaries in the context of emerging countries, we choose foreign subsidiaries in China as sampling targets. The sampled MNCs consist of Chinese-foreign joint ventures and wholly foreign-owned subsidiaries in China. The data for this study were collected in Wuhan city which locates in middle area of China. The questionnaires were distributed and collected by one Chinese author. Some questionnaires were distributed and collected by e-mail. The first set of data was collected from May to July of 2015. As it was insufficient, we collected a second set of data from August to September in 2015. In total, 200 questionnaires were distributed conveniently. Of them, 84 were collected (with a response rate of $42 \%$ ), and four were answered unfaithfully. Hence, valid samples are comprised of 80 companies, and they are used for statistical analysis.

Key informants of this study are 31 CEOs accounting for $38.75 \%$ of the respondents and 49 senior managers accounting for $61.25 \%$ of the respondents. HQs of sampled firms are based in the Europe (27.5\%), South Korea (17.5\%). Regards to the types of entry mode, 41 wholly-owned subsidiaries account for $51.25 \%$; 39 international joint ventures account for $48.75 \%$. Lastly, most of the sampled firms are with less than 10 years of experience $(45 \%)$ of international business experience, and other firms with more than 20 years $(28.75 \%)$ and with $10 \sim 20$ years $(26.25 \%)$.

\subsection{Reliability and Validity Test}

The results of a reliability test show that for eleven measured variables, their reliabilities were high as Cronbach's alpha values were greater than 0.7. Shared vision and cultural distance were also within reliable limits despite its Cronbach's alpha value of under 0.6. As the unit of analysis in this study is an organization, the Cronbach's alpha value of greater than 0.5 was enough to confirm the reliability of the measurement (see Table 1). 
Table 1. Reliability Analysis

\begin{tabular}{|c|c|c|c|c|c|}
\hline & \multicolumn{2}{|c|}{ Variables } & \multirow{2}{*}{$\begin{array}{c}\text { Cronbach's } \alpha \\
.766\end{array}$} & \multicolumn{2}{|c|}{$\begin{array}{l}\text { Changes of } \\
\text { item number }\end{array}$} \\
\hline \multirow{12}{*}{$\begin{array}{l}\text { Independent } \\
\text { variable }\end{array}$} & \multirow[t]{3}{*}{ HQ } & Sender's motivation & & 5 & 5 \\
\hline & & Knowledge stock & .652 & 3 & 3 \\
\hline & & Expatriates & .790 & 3 & 3 \\
\hline & Overseas & Receivers willingness & .718 & 5 & 3 \\
\hline & Subsidiaries & Absorptive capacity & .621 & 4 & 2 \\
\hline & & Inpatriates & .685 & 5 & 3 \\
\hline & Communication & Language barrier & .741 & 4 & 3 \\
\hline & Gap & Shared vision & .528 & 3 & 3 \\
\hline & & Information technology & .777 & 4 & 4 \\
\hline & Culture & Cultural distance & .539 & 3 & 2 \\
\hline & & Trust & .638 & 5 & 3 \\
\hline & & Teamwork & .869 & 4 & 4 \\
\hline $\begin{array}{l}\text { Dependent } \\
\text { variable }\end{array}$ & & wledge Gap & .878 & 3 & 3 \\
\hline
\end{tabular}

In order to extract all variables' composite elements, we used the principal component analysis. Varimax method was used to simplify the values the factors loaded on. The items whose loading values were less than 0.5 were eliminated. The resulting analysis confirmed that all of the retained factors' loading values were greater than 0.5 , and their Eigen values were greater than 1. The validities of all variables were high enough for statistical analysis.

\subsection{Correlations Analysis}

The Pearson correlation analysis was utilized to test the correlations among 13 variables. As shown in Table 5, most of independent variables exhibit weak positive correlations. And as expected, a negative correlation exists between language barrier and knowledge gap.

Table 2. Correlation Analysis

\begin{tabular}{|c|c|c|c|c|c|c|c|c|c|c|c|c|c|}
\hline & SM & KS & EXP & RW & AC & INP & SV & LB & IT & CD & TW & TR & KG \\
\hline SM & 1.000 & $.222^{*}$ & $.281^{*}$ & $.431^{* *}$ & $.365^{* *}$ & $.361^{* *}$ & $.291^{* *}$ & .176 & $.253^{*}$ & $.385^{* *}$ & $.407^{* *}$ & $.344^{* *}$ & $.379^{* *}$ \\
\hline KS & & 1.000 & $.346^{* *}$ & $.422^{* * *}$ & .176 & $.396^{* *}$ & .154 & .171 & $.428^{* *}$ & $.306^{* *}$ & $.323^{* *}$ & .165 & .175 \\
\hline EXP & & & 1.000 & $.442^{* *}$ & $.267^{*}$ & $.358^{* * *}$ & $.340^{* *}$ & -.060 & $.252^{*}$ & .190 & .088 & .126 & .115 \\
\hline $\mathbf{R W}$ & & & & 1.000 & $.277^{*}$ & $.461^{* *}$ & $.278^{*}$ & .170 & $.370^{* *}$ & $.278^{*}$ & $.310^{* *}$ & .127 & .140 \\
\hline $\mathbf{A C}$ & & & & & 1.000 & $.321^{* *}$ & $.260^{*}$ & $.238^{*}$ & $.349^{* *}$ & $.413^{* *}$ & .184 & $.460^{* *}$ & $.442^{* *}$ \\
\hline INP & & & & & & 1.000 & $.228^{*}$ & .172 & $.327^{* *}$ & $.360^{* *}$ & $.349^{* *}$ & $.275^{*}$ & $.303^{* *}$ \\
\hline SV & & & & & & & 1.000 & .089 & .201 & $.271^{*}$ & .138 & $.232^{*}$ & $.398^{* *}$ \\
\hline LB & & & & & & & & 1.000 & $.327^{* *}$ & .195 & .029 & .112 & -.031 \\
\hline IT & & & & & & & & & 1.000 & $.374^{* *}$ & $.244^{*}$ & $.369^{* *}$ & $.298^{* *}$ \\
\hline CD & & & & & & & & & & 1.000 & $.483^{* *}$ & $.462^{* *}$ & $.386^{* *}$ \\
\hline TW & & & & & & & & & & & 1.000 & $.546^{* *}$ & $.579^{* *}$ \\
\hline TR & & & & & & & & & & & & 1.000 & $.545^{* *}$ \\
\hline KG & & & & & & & & & & & & & 1.000 \\
\hline
\end{tabular}

- Note: sample size $\mathrm{N}=80,{ }^{*}: \mathrm{p}<0.05,{ }^{\star *}: \mathrm{p}<0.01$ 


\subsection{Results of a Hierarchical Regression Analysis}

Our hypotheses focus on the key variables that affect the knowledge transfer between a HQ and overseas subsidiaries. To test empirically our 12 hypotheses, we used a hierarchical regression analysis (see Table 3). In a Model 1, we included only transfer actors (HQ and overseas subsidiaries) related variables, producing its $\mathrm{R}$-square of $0.234(\mathrm{p}<0.01)$. Next, in a Model 2, we added transfer media variables reflecting a communication gap, and R-square increased significantly $(0.369, \mathrm{p}<0.01)$. Lastly, in a Model 3, we added transfer context variables reflecting a culture gap, and R-Square increased more significantly $(0.526, \mathrm{p}<0.01)$. The significant changes in $\mathrm{R}$-square demonstrate the explaining power of the variables of the three gaps model. We estimated variance inflation factors (VIF) for each model to examine multicollinearity and found that they were below the harmful levels.

Specifically, in a Model 1, we mainly tested the transfer actors' (including a sender and a receiver) roles in reducing the knowledge gap. According to the result, absorptive capacity's $\beta$ showed a positive value (0.440) and was statistically significant under $1 \%$ level of significance, supporting its positive effect on the knowledge gap reduction. Regression analysis yielded $\mathrm{R}$ square $=0.234, \mathrm{~F}=3.708$ $(\mathrm{p}<0.01)$. In conclusion, absorptive capacity of overseas subsidiaries has a positive effect on the knowledge gap reduction. H5 is supported.

In a Model 2, we added the transfer media variables (communication gap) and tested if they are positively or negatively affecting the knowledge gap reduction. According to the result, regression analysis yielded $\mathrm{R}$ square $=0.369, \mathrm{~F}=4.533$ $(\mathrm{p}<0.01)$, and shared vision's $\beta$ showed a positive value $(0.328)$ and was statistically significant under $0.5 \%$ level of significance, supporting its positive effect on the knowledge gap reduction. At the same time, language barrier's $\beta$ showed a negative value (-0.461) and was statistically significant under $0.1 \%$ level of significance, thus supporting a negative effect on knowledge gap reduction. Therefore, shared vision is positively, and language barrier is negatively affecting the knowledge gap reduction. $\mathrm{H} 7$ and $\mathrm{H} 8$ are supported.

In a Model 3, we added the transfer context variables (culture gap) and tested if they are positively or negatively affecting the knowledge gap reduction. According to the result, regression analysis yielded $\mathrm{R}$ square $=0.526, \mathrm{~F}=6.196(\mathrm{p}<0.01)$, and trust's $\beta$ value showed a positive value $(0.405)$ and was statistically significant under $0.5 \%$ level of significance, supporting its positive effect on the knowledge gap reduction. Teamwork's $\beta$ showed a positive value $(0.367)$ and was statistically significant under $0.5 \%$ level of significance, supporting its positive effect on the knowledge gap reduction. Thus $\mathrm{H} 11$ and $\mathrm{H} 12$ are supported. At the same time, absorptive capacity, shared vision and language barrier continue keeping positive effects on the knowledge gap reduction.

To sum up, H1-H4, H6, H9-10 are rejected, and H5, H7-8, H11-12 are accepted. 
Table 3. Regression Analysis

\begin{tabular}{|c|c|c|c|c|c|c|c|}
\hline \multicolumn{2}{|c|}{ Independent variable } & \multicolumn{2}{|c|}{ Model 1} & \multicolumn{2}{|c|}{ Model 2} & \multicolumn{2}{|c|}{ Model 3} \\
\hline & & Beta & $\mathrm{t}$ & Beta & $\mathrm{t}$ & Beta & $\mathrm{t}$ \\
\hline \multirow{6}{*}{$\begin{array}{c}\text { Transfer } \\
\text { Actors } \\
\text { (HQ and } \\
\text { Overseas } \\
\text { subsidiaries ) }\end{array}$} & Sender's motivation & .289 & 1.694 & .269 & 1.678 & .116 & .777 \\
\hline & Knowledge stock & .142 & .774 & .132 & .737 & .030 & .189 \\
\hline & Expatriates & -.058 & -.412 & -.217 & -.1 .589 & -.118 & -.957 \\
\hline & Receiver's willingness & -.152 & -.844 & -.181 & -1.070 & -.125 & -.803 \\
\hline & Absorptive capacity & .440 & $2.841 * *$ & .459 & $3.035 * *$ & .325 & $2.244^{*}$ \\
\hline & inpatriates & .149 & .814 & .169 & .979 & .022 & .138 \\
\hline \multirow{3}{*}{$\begin{array}{c}\text { Transfer } \\
\text { Media } \\
\text { (communication } \\
\text { gap ) }\end{array}$} & Shared vision & & & .328 & $2.432 *$ & .289 & $2.399 *$ \\
\hline & Language barrier & & & -.461 & $-2.961 * *$ & -.361 & $-2.585^{*}$ \\
\hline & Information technology & & & .276 & 1.450 & .210 & 1.203 \\
\hline \multirow{3}{*}{$\begin{array}{c}\text { Transfer } \\
\text { Context } \\
\text { (culture gap) }\end{array}$} & Cultural distance & & & & & -.019 & -.132 \\
\hline & Trust & & & & & .405 & $2.021 *$ \\
\hline & Teamwork & & & & & .367 & $2.585 *$ \\
\hline & $\mathbf{F}$ & \multicolumn{2}{|c|}{$3.708 * *$} & \multicolumn{2}{|c|}{$4.533 * *$} & \multicolumn{2}{|c|}{$6.196 * *$} \\
\hline & $\mathbf{R}^{2}$ & \multicolumn{2}{|c|}{0.234} & \multicolumn{2}{|c|}{0.369} & \multicolumn{2}{|c|}{0.526} \\
\hline
\end{tabular}

\section{Discussion and Conclusion}

In facing the exponential growth of global competition, knowledge has become the most strategically important resource to MNCs [9]. Intra-MNC's knowledge transfer is a hot topic for scholars in international business. Previous research has bundled various factors into two main categories: capacity and motivation. We diverged from the previous studies' research orientation to focus on gaps which exist between HQs and foreign subsidiaries.

To develop a comprehensive model explaining knowledge transfer between HQs and foreign subsidiaries, we designed the conceptual framework called 'a three gaps model of intra-MNC's knowledge transfer.' We conceptualized intra-MNC's knowledge transfer as a knowledge gap reduction process. The success of knowledge transfer may be possible by reducing knowledge gaps between HQ and overseas subsidiaries. MNCs, therefore, should overcome various barriers widening the knowledge gap between HQs and subsidiaries. The more successful the knowledge transfer is, the more the knowledge gap is reduced. Three gaps model offer a multi-dimensional view of MNC's knowledge transfer and depict the causal relationship between three types of gaps and success of knowledge transfer.

With the three gaps model, we examined how the knowledge gap is reduced and the success of knowledge transfer is achieved between the HQ and overseas subsidiaries. Through empirical analysis, we found that overseas subsidiaries' absorptive capacity (Hypothesis 5), communication gap's shared vision (Hypothesis 8), culture gap's trust (Hypothesis 11) and teamwork (Hypothesis 12) have significant positive effects on reducing knowledge gap. At the same time, communication gap's language barrier (Hypothesis 7) has a negative effect on reducing knowledge gap.

Based on the empirical results, we can draw the following conclusions. First, while the existing literature focused the importance of the transfer process (Szulanski, 2000), we focused on the role of transfer actors in the intra-MNC's knowledge transfer. We confirmed that transfer actors' absorptive capacity played an important role in the intra-MNC's knowledge transfer. However, we failed to find statistical evidence that other factors had significant effect on the knowledge transfer. It was only found the 
support for the argument that the absorptive capacity of subsidiaries facilitated the intra-MNC's knowledge transfer.

Second, this research has broadened our understanding of MNCs' knowledge transfer process. We found that two types of gaps (communication gap and culture gap) have effect on the knowledge transfer. Through enhanced trust, reduced language barriers, teamwork and shared vision, the knowledge gap between HQ and overseas subsidiaries could be reduced, and the transfer of knowledge would be facilitated.

Last, even there exists a growing body of research on the specific relationship between HQ and overseas subsidiaries, our study focused on the gaps between HQ and subsidiaries, that is, communication gap and culture gap. Successful cross-cultural knowledge transfer requires a variety of organizational capabilities, such as capabilities to adapt to unfamiliar host cultures, to understand local management practices, to communicate with local language and to build teamwork and partnership. Comprehensive factors will contribute to the success of a cross-cultural knowledge transfer.

With empirical findings, we can suggest some strategic implications: first of all, absorptive capacity, trust, teamwork and shared vision will positively reduce the knowledge gap between HQs and overseas subsidiaries; at the same time, language barrier will negatively reduce the knowledge gap between HQs and overseas subsidiaries. Therefore, MNCs should figure out effective strategies by utilizing these factors in order to reduce knowledge gap between HQs and overseas subsidiaries. We strongly believe that the three gaps model could help MNCs' knowledge transfer, and verified variables are applicable to other MNCs.

Second, a MNC manager who takes charge of knowledge transfer should be more concerned with the level of knowledge gap between HQs and overseas subsidiaries. As the knowledge gap between senders and receivers may negatively affect transfer success, the manager in duty has to assess whether receivers have an enough level of absorptive capacity which includes receiving, absorbing, and re-using capacity of the transferred knowledge. If the knowledge gap is large, a knowledge intermediary might be required. Additionally, the process of knowledge transfer within MNCs is defined as a two-way communication, in which the intended goal is reducing knowledge gap between HQs and overseas subsidiaries.

However, our paper had some limitations. For instance, empirical analysis is restricted by a sample selection, in our case, foreign subsidiaries in China. We need more empirical evidences for the establishment of external validity. Even a three gaps model provides a platform for the basic understanding of the knowledge transfer process between HQ and overseas subsidiaries, it is unclear that other factors, for example, political or institutional factors, might dominate in an emerging economy. In a future study, therefore, it is worthwhile that these potential dimensions receive more attention.

\section{Appendix}

\section{Measurement of Sender's Motivation:}

1 In HQ, there are incentives systems to facilitate knowledge transfer to overseas subsidiaries.

2 In HQ, there are reward systems to facilitate knowledge transfer to overseas subsidiaries.

$3 \mathrm{HQ}$ is willing to shared information with overseas subsidiaries.

$4 \mathrm{HQ}$ is willing to interact and exchange ideas with overseas subsidiaries.

$5 \mathrm{HQ}$ is willing to solve difficulties in transferring knowledge to subsidiaries.

Measurement of knowledge stock:

$1 \mathrm{HQ}$ has highly skilled employees.

$2 \mathrm{HQ}$ develops new ideas and creates new knowledge.

$3 \mathrm{HQ}$ acquires new knowledge from customers, suppliers, and alliance partners. 
Measurement of expatriates:

1 In HQ, there are some employees who have the experience of living in a particular host country.

2 In HQ, there are some employees who have the capability of developing personal relations with local staffs.

3 In HQ, there are some employees who can speak the host country's language.

Measurement of receiver's willingness:

1 In overseas subsidiaries, there are incentives systems to encourage employees to seek and use new knowledge from HQ.

2 In overseas subsidiaries, there are reward systems to encourage employees to seek and use new knowledge from HQ.

3 Overseas subsidiaries are willing to acquire information from HQ.

4 Overseas subsidiaries are willing to interact and exchange ideas with HQ employees.

5 Overseas subsidiaries are willing to solve difficulties in obtaining knowledge from HQ.

Measurement of absorptive capacity:

1 Overseas subsidiaries have the ability to acquire knowledge from HQ.

2 Overseas subsidiaries have the technical competency to absorb knowledge from HQ.

3 Overseas subsidiaries have the ability to assimilate knowledge from HQ.

4 Overseas subsidiaries have the ability to exploit knowledge from HQ.

Measurement of inpatriates:

1 In overseas subsidiaries, there are some employees who are willing to make personal contacts with HQ staff.

2 In overseas subsidiaries, there are some employees who think that it is important for them to establish close working relationships with as many HQ staff as possible.

3 In overseas subsidiaries, there are some employees who see themselves as a key person who links employees at the HQ.

4 In overseas subsidiaries, there are some employees who concentrate on establishing relationships with employees at the HQ who are useful for their learning and professional development.

5 In overseas subsidiaries, there are some employees who concentrate on establishing relationships with employees at the HQ who are useful for their career advancement.

Measurement of shared vision:

1 Our company has a coherent organizational culture.

2 Our company has shared ambitions.

3 Our company is putting an integrated network between HQ and overseas subsidiaries into practice.

Measurement of language barrier:

1 Our company chooses one common language as the "corporate language."

2 Our company selectively recruits employees who have a foreign language capability.

3 Our company has a language training program.

4 our company uses external language resources.

Measurement of information technology:

1 Our company provides internal or external support services for communication technology.

2 Our company carries out knowledge management using ICT.

3 Our company facilitates the development of ICT infrastructure.

4 Our company supports ICT application between HQ and overseas subsidiaries.

Measurement of cultural distance:

1 Our company encourages a global mindset.

2 Our company encourages employee to learn more about cross-cultural learning.

3 There are similar social manners between the HQ and overseas subsidiaries.

Measurement of trust:

1 HQ has a high reputation in the process of knowledge transfer.

2 HQ sees no reason to doubt overseas subsidiaries' competence and preparation.

3 Overseas subsidiaries are highly trustworthy in the process of knowledge transfer.

4 Overseas subsidiaries believe that HQ approaches its knowledge with professionalism and dedication.

5 Overseas subsidiaries' operation performance relies heavily on some decision-making from HQ. 


\section{Measurement of teamwork:}

1 There is a high degree of group affiliation in our company.

2 There is a high degree of staff loyalty in our company.

3 There is a high degree of cultural collectivism in our company.

4 There is a high degree of frequent interactions between HQ and overseas subsidiaries.

\section{Measurement of knowledge gap}

1 There is a lot of knowledge that overseas subsidiaries should learn from HQ.

2 Overseas subsidiaries' operations are largely supported with information provided by HQ.

3 The new product or strategy developed in HQ are easy to understand by overseas subsidiaries

\section{Acknowledgments}

This work was supported by a 2-Year Research Grant of Pusan National University.

\section{References}

[1] V. Albino, A. Garavelli and G. Schiuma, "Knowledge transfer and inter-firm relationships in industrial districts: The role of the leader firm", Technovation, vol. 19, no. 1, (1998), pp. 53-63.

[2] M. J. Ashleigh and J. Nandhakumar, "Trust and technologies: Implications for organizational work practices”, Decision Support Systems, vol. 43, no. 2, (2007), pp. 607-617.

[3] P. J. Buckley, M. J. Carter, J. Clegg and H. Tan, "Language and social knowledge in foreign-knowledge transfer to china", International Studies of Management \& Organization, vol. 35, no.1, (2005), pp. 47-65.

[4] J. Chen and R. J. McQueen, "Knowledge transfer processes for different experience levels of knowledge recipients at an offshore technical support center,' Information Technology \& People, vol. 23, no.1, (2010), pp. 54-79.

[5] Y. Duan, W. Nie and E. Coakes, "Identifying key factors affecting transnational knowledge transfer", Information \& Management, vol. 47, no. 7, (2010), pp. 356-363.

[6] A. K. Gupta and V. Govindarajan, "Knowledge flows within multinational corporations", Strategic Management Journal, vol. 21, no.4, (2000), pp. 473-496.

[7] M. Harvey, C. Speier and M. M. Novicevic, "The role of inpatriation in global staffing", International Journal of Human Resource Management, vol. 10, no.3, (1999), pp. 459-476.

[8] B. Kogut and U. Zander, "Knowledge of the firm, combinative capabilities, and the replication of technology", Organization Science, vol. 3, no. 3, (1992), pp. 383-397.

[9] B. Kogut and U. Zander, "Knowledge of the firm and the evolutionary theory of the multinational corporation", Journal of International Business Studies ,vol. 24, no. 4, (1993), pp. 625-645.

[10] L. Li, "The effects of trust and shared vision on inward knowledge transfer in subsidiaries' intra-and inter-organizational relationships", International Business Review, vol. 14, no.1, (2005), pp. 77-95.

[11] C. Marcotte and J. Niosi, "Technology transfer to china: The issues of knowledge and learning", The Journal of Technology Transfer, vol. 25, no.1, (2000), pp. 43-57.

[12] I. Nonaka and H. Takeuchi, "The Knowledge Creation Company: How Japanese Companies Create the Dynamics of Innovation”, (1995).

[13] W. Shan and J. Song, "Foreign direct investment and the sourcing of technological advantage: Evidence from the biotechnology industry", Journal of International Business Studies, vol. 28, no.2, (1997), pp. 267-284.

[14] B. L. Simonin, "Ambiguity and the process of knowledge transfer in strategic alliances", Strategic Management Journal, vol. 20, no.7, (1999), pp. 595-623.

[15] G. Szulanski, "Exploring internal stickiness: Impediments to the transfer of best practice within the firm", Strategic Management Journal, vol. 17, no.S2, (1996), pp. 27-43.

[16] G. Szulanski, "The process of knowledge transfer: A diachronic analysis of stickiness", Organizational Behavior and Human Decision Processes, vol. 82, no.1, (2000), pp. 9-27.

[17] F. Wang and H. Bang, "Explaining MNC's knowledge transfer using two gaps model", Advanced Science and Technology Letters, vol.114, Business (2015), pp.116-122.

[18] Q. Yang, R. Mudambi and K. E. Meyer, "Conventional and reverse knowledge flows in multinational corporations", Journal of Management, vol. 34, no.5, (2008), pp. 882-902. 


\section{Authors}

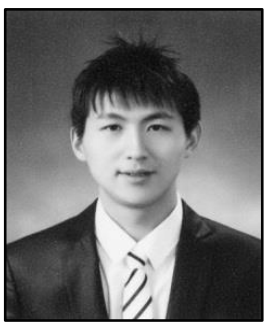

Wang-Fang is a Ph. D. candidate of Graduate School at the Pusan National University, Korea. His research interests are in international business and international knowledge transfer.

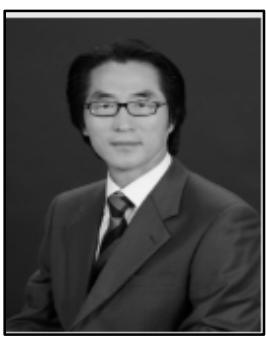

Ho-Yeol Bang is Professor of International Business and Strategic Management at the Pusan National University, Korea. He received his $\mathrm{Ph}$. D. from Korea University. His research interests are in international business, strategic management, and knowledge management. He published several books including International Business (2008) and Strategic Management (2014). His research work has been published in numerous academic journals in Korea and USA. 
International Journal of $\mathrm{u}-$ and $\mathrm{e}-$ Service, Science and Technology Vol.9, No. 4 (2016) 